\title{
Perfil dos consumidores de hortaliças minimamente processadas de Belo Horizonte
}

\author{
Ronaldo Perez; Afonso Mota Ramos; Mirella Lima Binoti; Paulo Henrique Machado de Sousa; Gisela de \\ Magalhães Machado; Iara Borges Cruz \\ UFV-Depto. Tecnol. de Alimentos, 36570-000 Viçosa-MG; rperez@ufv.br; amramos@ufv.br; phenriquemachado@gmail.com
}

\begin{abstract}
RESUMO
O consumidor vem apresentando cada vez maior consciência na escolha de sua alimentação, porém com menor tempo disponível para preparar refeições saudáveis. Diante disso, o mercado de hortaliças minimamente processadas tem aumentado rapidamente, proporcionando o surgimento de produtos convenientes, ou seja, produtos frescos que podem ser preparados e consumidos em pouco tempo. Assim, neste trabalho estudou-se o comportamento de compra e o perfil dos consumidores de hortaliças minimamente processadas em supermercados de Belo Horizonte. Foram aplicados questionários aos consumidores de cinco estabelecimentos que vendiam hortaliças minimamente processadas (HMP) e os entrevistados foram escolhidos aleatoriamente no momento das compras, durante o mês de novembro de 2004. Foram entrevistadas 246 pessoas, das quais apenas $23 \%$ consumiam HMP. Os principais motivos para consumir foram comodidade e praticidade (46\%), pouco tempo para o preparo $(21 \%)$ das refeições e higiene $(11 \%)$ dos produtos, e para não consumir foram preço elevado $(31,9 \%)$, gosta de preparar e/ou escolher (23\%) e desconfiança $(17,8 \%)$ dos produtos ofertados. Os maiores consumidores são as pessoas com maior escolaridade e nível de renda mais elevado. A sobrevalorização dos HMP em relação aos produtos comuns variou de 2,4 vezes (batata) até 39,5 vezes (cenoura), sendo a média de sobrevalorização encontrada no mercado para as onze HMP de 10 vezes.
\end{abstract}

Palavras-chave: processamento mínimo, consumidor, pesquisa de mercado.

\begin{abstract}
Profile of minimally processed vegetable consumers in Belo Horizonte, Brazil

Consumer's food consciousness has increased, however, time for preparing healthy food has decreased. Therefore, the market of minimally processed vegetable has increased rapidly, giving rise to the appearance of fresh products that can be prepared and consumed faster than conventional foods. Thus, the objective of this work was to establish the behavior and profile of minimally processed vegetable consumers in supermarkets of Belo Horizonte, Minas Gerais State, Brazil. Based on the answers to a survey, the consumers profile was traced, highlighting preferences, habits, complaints and demands. The survey was conducted with consumers of five supermarkets which sell minimally processed vegetables (MPV). Consumers were chosen randomly when they were buying in November 2004. Of two hundred and forty six interviewed persons, $23 \%$ were consumers of MPV. The main reasons for consumption were: easiness and feasibility (46\%); short preparation time $(21 \%)$ of meals and hygiene $(11 \%)$ of the products; and the main reasons against consumption were: the high price of the precuts $(31,9 \%)$; easy to prepare and/or to choose $(23 \%)$ and distrusting $(17,8 \%)$ the offered products. The major consumers were those with a better education. Comparing the overrating of MPV with other vegetables, a variation of 2,4 (potato) to 39,5 times (carrots) was found. On average the overrating found in markets for eleven MPV was of 10 times.
\end{abstract}

Keywords: minimally processing, consumer, market research.

(Recebido para publicação em 22 de novembro de 2007; aceito em 30 de outubro de 2008) (Received in November 22, 2007; accepted in October 30, 2008)

\begin{abstract}
$\mathrm{A}$ $\mathrm{s}$ hortaliças minimamente processadas (HMP) surgiram como uma interessante alternativa para o consumidor que não possui tempo de preparar sua refeição ou mesmo não gosta de fazê-la. Em vários países verifica-se que esses produtos estão sendo oferecidos nos formatos mais variados, sempre visando a agregação de valor e comodidade do consumidor (Candel, 2001; Moretti, 2004). Alguns estudos têm mostrado que a necessidade dos consumidores por conveniência é correlacionada com a escolha dos alimentos (Verbeke, 2001; Verlegh \& Candel, 1999). Normalmente na seção de frutas, legumes e verduras (FLV) dos
\end{abstract}

supermercados, esses produtos podem estar embalados em bandejas cobertas com filme plástico ou em pacotes. A atmosfera interna das embalagens pode ser modificada para aumentar o tempo de validade dos produtos.

De acordo com o "International Fresh-Cut Produce Association" (IFPA, 2001), produtos minimamente processados são frutas ou hortaliças que são modificadas fisicamente, mas que mantêm o seu estado fresco. Assim, é um produto fresco, tornado conveniente, com qualidade e segurança.

As etapas através das quais as hortaliças são minimamente transformadas são basicamente: pré-seleção, classifi- cação, lavagem, corte, sanitização, enxágüe, centrifugação, embalagem e armazenamento refrigerado (Silva \& Fernandes, 2003).

São diversas as vantagens que as hortaliças minimamente processadas trazem para o produtor e também para o consumidor. A atividade normalmente mal remunerada de produção e venda de produtos hortícolas ao natural ganha especial incremento com a agregação de valor que o processamento mínimo proporciona ao produto. $\mathrm{O}$ consumidor ganha comodidade e praticidade devido a embalagens convenientes e um produto pronto para o preparo ou até mesmo para o consumo. 


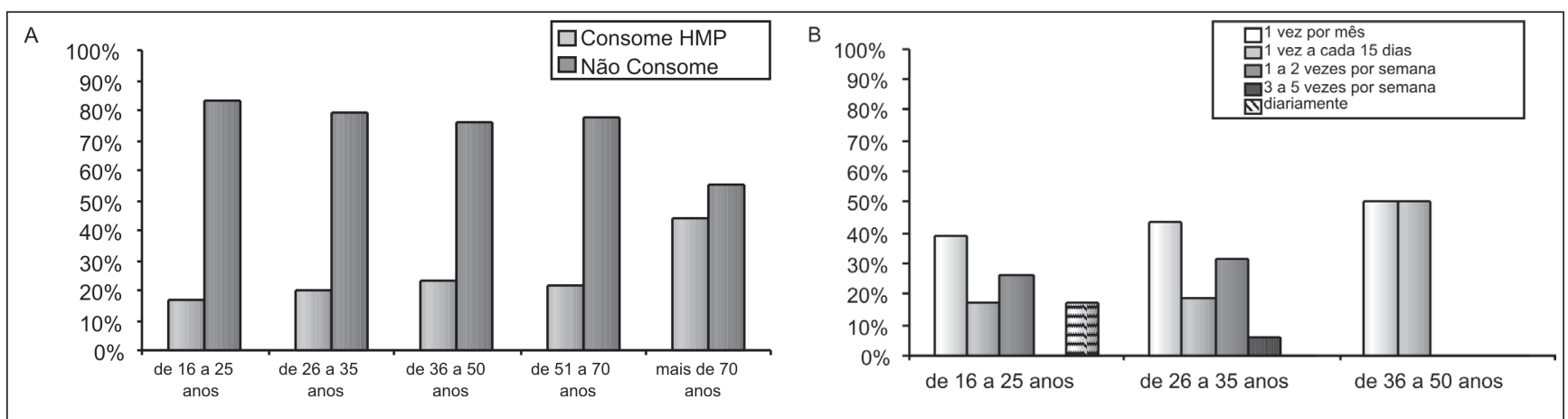

Figura 1. Consumo (A) e frequiência de consumo (B) de hortaliças minimamente processadas com relação à faixa etária dos entrevistados (). Viçosa, UFV, 2004.

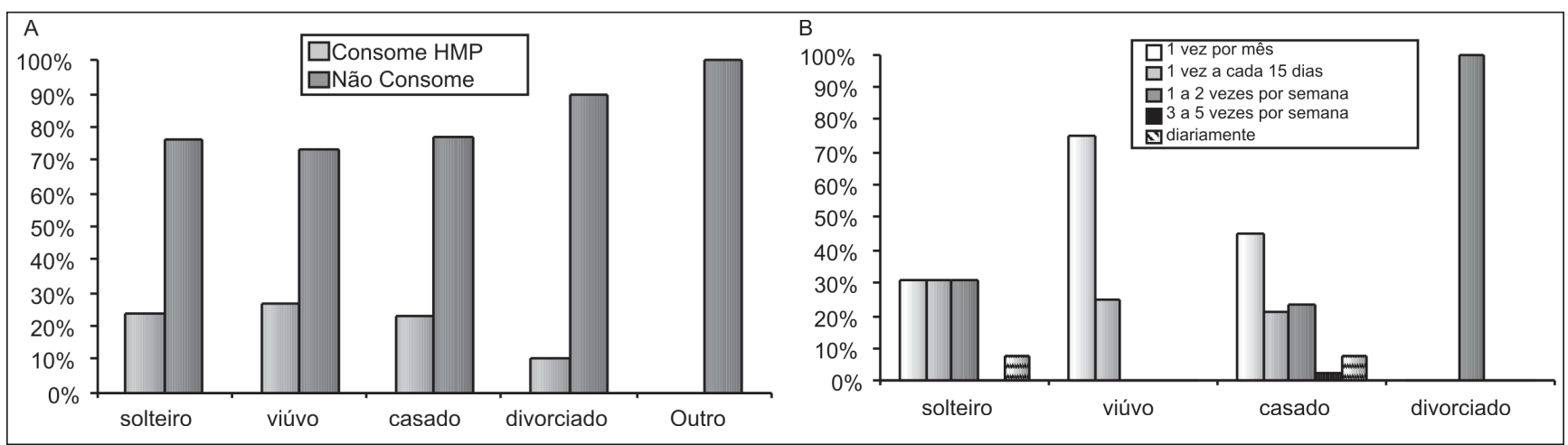

Figura 2. Consumo (A) e frequiência de consumo (B) de hortaliças minimamente processadas em relação ao estado civil. Viçosa, UFV, 2004.

O conhecimento do perfil dos consumidores é fundamental para que o produtor e sua associação ou cooperativa possam adequar sua oferta às necessidades específicas do público a ser atendido, quer por faixa de renda ou etária, por região geográfica ou por número de pessoas na família (FrutiFatos, 2003a). Diante do exposto, neste trabalho objetivou-se estabelecer o perfil de consumo de hortaliças minimamente processadas em Belo Horizonte (MG), bem como avaliar a qualidade e segurança através da análise da forma de armazenamento desses produtos.

\section{MATERIAL E MÉTODOS}

A população pesquisada consistiu de consumidores que compravam hortaliças minimamente processadas em cinco estabelecimentos comerciais (supermercados), situados em diferentes áreas da cidade de Belo Horizonte, durante o mês de novembro de 2004. Esses estabelecimentos foram selecionados por venderem hortaliças minimamente processadas nas mais diferentes formas. Os consumidores foram selecionados aleatoriamente no momento das compras, durante os dias da semana e finais de semana, nos períodos da manhã, tarde e noite.

A pesquisa foi realizada seguindo metodologia específica da modalidade exploratória, que inclui aplicação de questionários e entrevistas aos agentes interessados. Andreuccetti et al. (2005) e Wilkins et al. (2002) utilizaram questionários e entrevistas como meio de coletar informações junto aos consumidores, justificando que esta é uma metodologia fácil e rápida para obtenção de dados.

Os questionários foram elaborados para caracterizar o consumidor; suas preferências, e o consumo em relação ao produto estudado. Também foram aplicados questionários aos responsáveis pela seção de FLV dos supermercados pesquisados para analisar o percentual de venda dos HMP e quais eram as hortaliças mais vendidas. $\mathrm{O}$ número de consumidores entrevistados foi calculado considerando-se o tamanho da população, a homogeneidade do público alvo e a quantidade de erro amostral admitida. Foi considerado um erro amostral de $\pm 5 \%$ e um público alvo homogêneo em relação ao padrão de consumo. Como a cidade de Belo Horizonte tem 2.350.564 habitantes (IBGE, 2004) foi necessário aplicar 246 questionários aos consumidores nos estabelecimentos selecionados (SEBRAE/ EMBRAPA, 2003).

A forma de armazenamento das hortaliças minimamente processadas foi avaliada considerando-se o local e temperatura de armazenamento, forma de exposição, rotulagem e selo de qualidade. O armazenamento é relevante dada sua maior importância em relação à qualidade e segurança dos alimentos minimamente processados (Jacxsens et al., 2002a, 2002b; Piga et al., 2000).

Os dados obtidos nas entrevistas foram analisados utilizando o programa estatístico SPSS ${ }^{\circledR}$ para Windows, pela análise de agrupamentos e realizada análise gráfica dos dados.

\section{RESULTADOS E DISCUSSÃO}

Em Minas Gerais, um total de 83 e $80 \%$ das pessoas pesquisadas consome legumes e verduras, respectivamente, 


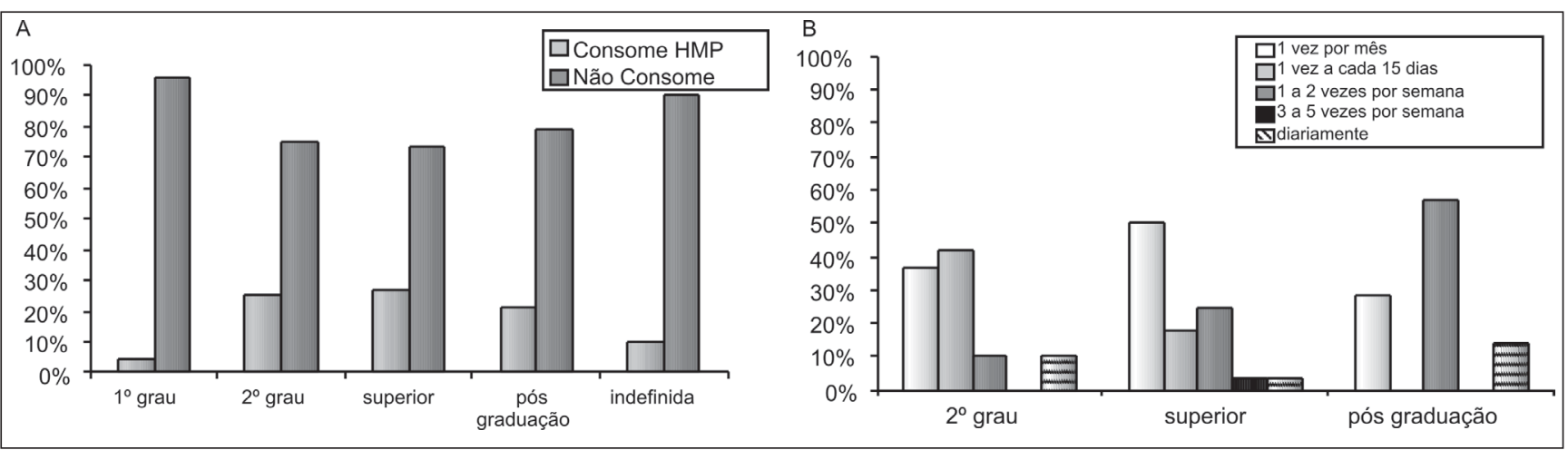

Figura 3. Consumo (A) e freqüência de consumo (B) de hortaliças minimamente processadas em relação à escolaridade dos entrevistados. Viçosa, UFV, 2004.
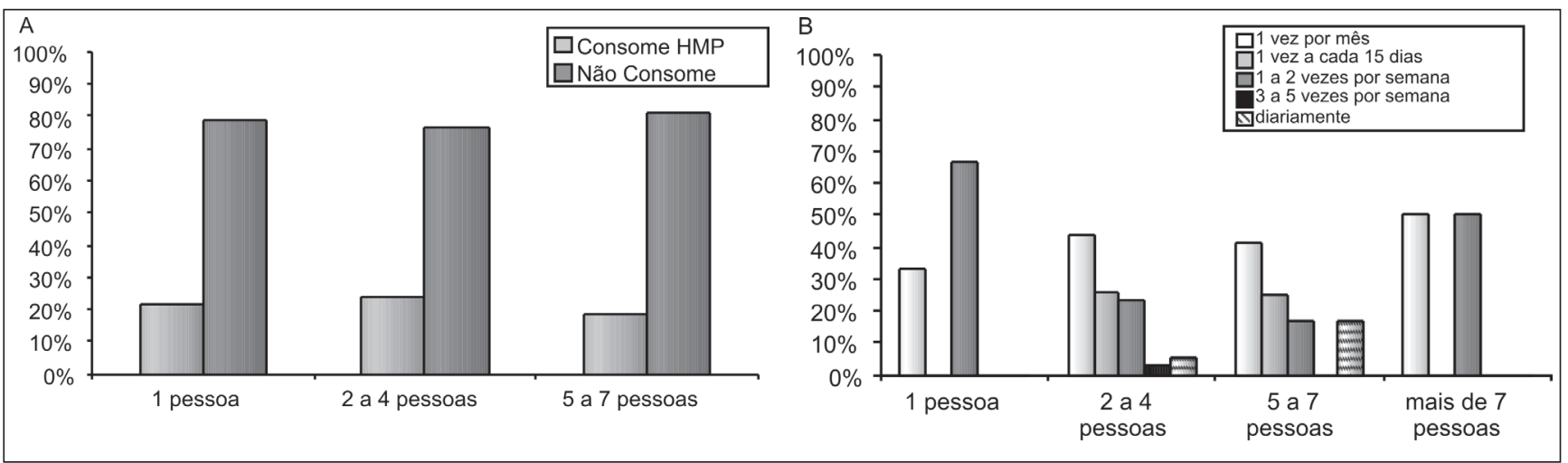

Figura 4 Consumo (A) e freqüência do consumo (B) de hortaliças minimamente processadas em relação ao número de moradores. Viçosa, UFV, 2004.

todos os dias da semana. Já no Rio de Janeiro, quase metade da população, $57 \%$ em média, tem o hábito de consumir os hortifrútis diariamente, e $10 \%$ o fazem três ou quatro vezes por semana (FrutiFatos, 2003b). Os legumes são consumidos diariamente por cerca de $60 \%$ da população e as verduras por $57 \%$. Comparado aos mineiros, a pesquisa indicou que os cariocas dão menos importância ao consumo de frutas e hortaliças e apenas $46 \%$ os julgam alimentos saudáveis contra $60 \%$ dos mineiros (FrutiFatos, 2003b).

No presente trabalho todos os entrevistados (246) disseram que consomem hortaliças, sendo que $218(89 \%)$ consomem diariamente, 20 (8\%) consomem de 3 a 5 vezes por semana e $8(3 \%)$ consomem de 1 a 2 vezes por semana. Quanto às hortaliças minimamente processadas, dos entrevistados, $190(77 \%)$ não as consomem, e 56 (23\%) consomem estes produtos. A maior parte dos entrevistados $(74 \%)$ era do sexo feminino, indicando que a mulher é responsável pelas compras da casa, número inferior ao observado em Brasília, onde
$67,8 \%$ dos clientes avaliados eram mulheres, representando $56,4 \%$ dos consumidores de HMP (Junqueira et al., 2003).

A totalidade das pessoas abordadas dizia consumir hortaliças diariamente, porém o consumo de HMP é de apenas $23 \%$. Disso pode-se concluir que o consumo de hortaliças não processadas é bastante alto, o que caracteriza um mercado promissor para as hortaliças processadas, desde que sejam feitos ajustes para aumentar sua fatia de mercado, como redução nos preços e orientação quanto às suas vantagens em relação ao produto não processado.

Com relação ao consumo de hortaliças minimamente processadas, há uma pequena diferença entre as mulheres e os homens entrevistados. Entre os homens, o consumo de HMP é $25 \%$ um pouco maior que entre as mulheres (22\%). Entre os que consomem HMP, a maioria dos homens e mulheres consome raramente. Dos 246 entrevistados, apenas 56 consomem HMP, sendo este total representado por $71 \%$ de mulheres e $29 \%$ de homens. O consumo diário ocorre em $7 \%$; algumas vezes por semana (1 a 5 vezes) em $27 \%$; uma vez a cada 15 dias em $23 \%$ e 1 vez ao mês em $43 \%$. Com relação a este consumo, entre os homens (44\%) o consumo diário ou algumas vezes por semana é maior que entre mulheres (30\%), o que pode ser devido ao fato de que homens tradicionalmente cozinham menos que mulheres

Os entrevistados apresentavam-se na faixa etária de 16 a mais de 70 anos. Desses, $70 \%$ possuem entre 36 e 70 anos, sendo que a maioria dos entrevistados $(40 \%)$ apresentava entre 36 e 50 anos (Figura 1A). Podemos observar que o consumo é maior no grupo de idosos com mais de 70 anos em que $44 \%$ consomem HMP. Do total dos entrevistados que consomem HMP, 7\% são idosos com mais de 70 anos, e no grupo que não consome apenas 3\%. Apesar das pessoas com mais de 70 anos apresentarem um consumo de HMP significativo, esse consumo é esporádico. O consumo entre as pessoas mais novas é mais constante no tempo (Figura 1B). Junqueira et al. (2003) observaram no Distrito Federal um grupo constituído 


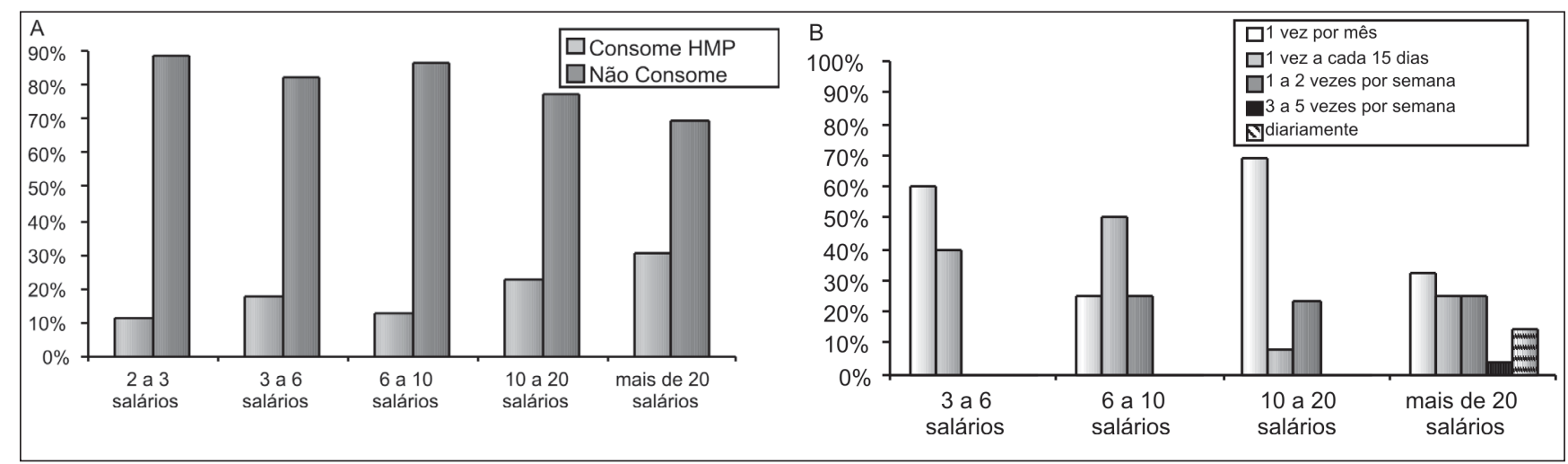

Figura 5. Consumo (A) e frequiência do consumo (B) de hortaliças minimamente processadas em relação entre renda familiar. Viçosa, UFV, 2004.

por pessoas na faixa etária de 21 a 30 anos $(32,0 \%)$, seguido pelos que estão na faixa de 41 a 50 anos $(28,1 \%)$.

A maior parte dos entrevistados $(66,6 \%)$ é casada. O padrão de consumo de HMP entre solteiros, viúvos e casados está em torno dos $20 \%$, enquanto que entre os divorciados $(4,1 \%$ dos entrevistados) essa porcentagem é ainda menor (10\%) (Figura 2A). Esperava-se que solteiros consumissem HMP com mais intensidade, devido à praticidade e economia de tempo que esses produtos proporcionam. No entanto, praticamente não houve diferença de consumo entre esse grupo e os outros.

As pessoas viúvas consomem hortaliças processadas com menor freqüência que os outros grupos discutidos. Os casados e os solteiros consomem mais vezes, porém o consumo esporádico (1 vez por mês) entre os casados (44\%) é maior que entre os solteiros (30\%). Dentro do grupo de pessoas casadas a maior freqüência de consumo de HMP é 1 vez ao mês, o que não acontece entre os solteiros, em que as frequiências são bem distribuídas, em torno de 30\% (Figura 2B).

Com relação à escolaridade, $42 \%$ dos entrevistados têm curso superior. $\mathrm{O}$ consumo de HMP entre as pessoas com diferentes graus de escolaridade não difere muito, estando em torno de $25 \%$. Entre as pessoas que possuem apenas o $1^{\circ}$ grau, menos de 5\% consomem HMP, porém este fato também pode estar mais relacionado à renda familiar, uma vez que $57 \%$ dessas pessoas ganham até 3 salários mínimos (Figura 3A). Este fato mostra que os maiores consumidores de hortaliças minimamente processadas possuem níveis de escolaridade e renda mais altos, estando de acordo com dados observados por Ragaert et al. (2004) e Leather (1995), onde grupos de mais alta renda consomem hortaliças mais caras e mais convenientes e que, quanto maior a escolaridade, maior a freqüiência de consumo de HMP.

Apesar da expectativa inicial de que as pessoas que moram sozinhas consumissem mais HMP que as famílias maiores, o que pôde ser observado é que o número de pessoas por domicílio foi indiferente quanto ao consumo do produto pesquisado (Figura 4A). Essa observação pode ser devida ao fato que as pessoas que moram sozinhas e não têm tempo para cozinhar, preferencialmente comem em estabelecimentos comercias. Porém, entre as pessoas que consomem HMP e moram sozinhas, o consumo frequente é maior que nos outros grupos, alcançando aproximadamente 70\% (Figura 4B).

Como as hortaliças minimamente processadas são vendidas a preços relativos elevados, a renda do consumidor faz diferença em relação à aquisição desses produtos. A maioria das pessoas abordadas (64\%) ganha mais de 10 salários mínimos, sendo que $39 \%$ do total de entrevistados possue renda familiar acima de 20 salários. Esses supermercados atendem a uma fatia de mercado que exige produtos diferenciados e com qualidade; portanto, sua clientela possui maior poder aquisitivo. Ainda, esse consumo é mais amiúde nessa clientela, chegando a $14 \%$ o número de entrevistados que consomem diariamente (Figuras 5A e 5B). Entre as pessoas com renda familiar maior que 20 salários mínimos existe a preocupação com o preço, pois essas pessoas muitas vezes podem ter cozinheiras para prepará-los, não precisando adquirir os produtos prontos. $\mathrm{O}$ hábito e o gosto de escolher e preparar verduras aparece como a segunda principal causa de repúdio a HMP, mesmo que essas pessoas possam pagar pela comodidade que esses produtos trazem. Conforme esperado, o preço elevado das hortaliças minimamente processadas é o principal motivo que leva a maior parte das pessoas $(31,9 \%)$ a não consumir o produto. Esse mesmo problema foi visto por Junqueira et al. (2003) e Ramos et al. (2005), que observaram que consumidores levam em consideração, no momento da compra, o preço e a qualidade das hortaliças minimamente processadas. Outro fator que afeta o consumo é o tamanho inadequado do produto, fato também observado por Junqueira et al. (2003). A falta de confiança é um motivo de peso e merece atenção (Tabela 1).

Entre os entrevistados na pesquisa, $59 \%$ (145 pessoas) são sempre responsáveis pelas compras da casa, $15 \%$ freqüentemente, $20 \%$ às vezes e $6 \%$ raramente responsáveis. Das 145 pessoas sempre responsáveis pelas compras, 112 (77\%) não consomem HMP. Para este grupo de entrevistados que consomem HMP, a maioria ( $52 \%$ ) tem seu consumo mensal. Já entre as pessoas que não são responsáveis pelas compras (às vezes e raramente), o consumo semanal ocorre apenas em $12 \%$ dos casos. Este fato pode estar ligado à facilidade de se comprar hortaliças embaladas e prontas, uma vez que as pessoas que não têm o hábito de fazer as compras do lar também não têm o hábito de escolher verduras. 
A maior parte dos entrevistados $(75 \%)$ considera importante que haja informações nos rótulos das hortaliças processadas. Destes, $52 \%$ acham que as informações fornecidas atualmente são insuficientes, sendo que apenas $23 \%$ consideram estas informações suficientes. Este grupo ressaltou que as informações nutricionais e tempo de consumo depois de aberto devem ser sempre fornecidas pelo produtor:

Os principais motivos que levaram os consumidores a adquirir HMP foram comodidade e praticidade, pouco tempo para o preparo das refeições e higiene dos produtos. Juntos, esses motivos perfazem $78 \%$ das respostas entre os consumidores de HMP (Tabela 1), estando de acordo com o observado por Ragaert et al. (2004).

Nesse sentido é preciso que haja mais propaganda e informação sobre hortaliças minimamente processadas para esclarecer as pessoas sobre a segurança e a qualidade desses produtos que são novos no mercado. Alguns dos fatores que levam as pessoas a não consumir os produtos são a não confiança $(17,9 \%)$, o desconhecimento $(7,8 \%)$ (Tabela 1).

Em todos os estabelecimentos pesquisados, os fornecedores estão cientes das reclamações. Nos casos em que há medidas corretivas, essas passam pela negociação com os fornecedores e exigências acerca de novos cortes e embalagens. Em alguns casos não existem medidas corretivas.

Os questionários aplicados aos responsáveis pela seção de FLV dos supermercados pesquisados demonstraram que a venda de hortaliças minimamente processadas ainda é pequena, perfazendo apenas $1 \%$ do total de vendas do estabelecimento na maioria dos casos, enquanto a venda de hortaliças em geral está entre 4 e 24\%. As HMP mais vendidas são "mix" de salada (20\%), cenoura (16\%), brócolis (15\%), alface (14\%) e couve (12\%), com $77 \%$ das vendas. Outros produtos são couve-flor $(9 \%)$, rúcula $(5 \%)$, mandioca $(4 \%)$, abobora (2\%) e espinafre (2\%). A exemplo do que verificaram Ramos et al. (2005), não há uma preferência absoluta por um determinado grupo de hortaliças.

$\mathrm{O}$ perfil de embalagem selecionado

Tabela 1. Motivos que levam ao consumo de hortaliças minimamente processadas entre os entrevistadores na cidade de Belo Horizonte (MG). Viçosa, UFV, 2004.

\begin{tabular}{lclr}
\hline \multicolumn{4}{c}{ Motivos para } \\
\hline Consumir & (\%) & Não consumir & (\%) \\
\hline Comodidade e praticidade & 46 & Preço elevado & 31,9 \\
Pouco tempo para preparo & 21 & Gosta de escolher e/ou preparar & 23,0 \\
Higiene dos produtos & 11 & Não confia & 17,9 \\
Ausência do não processado & 7 & Desconhece/ falta de hábito & 7,8 \\
Facilidade de manuseio das embalagens & 6 & Empregada & 5,8 \\
Saudável/ orgânico & 6 & Perda nutricional ou sensorial & 5,1 \\
Confia na marca & 1 & Produção própria & 3,5 \\
Maior rendimento & 1 & Outros & 2,4 \\
Diversificar & 1 & Come fora & 1,6 \\
\hline
\end{tabular}

Tabela 2. Preços médios de produtos comuns e minimamente processados na cidade de Belo Horizonte. Viçosa, UFV, 2004.

\begin{tabular}{lccc}
\hline Hortaliça & Comum $\mathbf{R} \mathbf{\text { kg }})$ & HMP $\mathbf{R} \mathbf{\text { }} \mathbf{k g})$ & Sobrevalorização \\
\hline Alface americana & 7,65 & 28,45 & 3,7 vezes \\
Alface crespa & 3,45 & 28,45 & 8,2 vezes \\
Alface lisa & 3,45 & 28,45 & 8,2 vezes \\
Alface roxa & 4,95 & 28,45 & 5,7 vezes \\
Batata & 1,25 & 2,98 & 2,4 vezes \\
Beterraba & 0,78 & 2,98 & 3,8 vezes \\
Cenoura & 0,72 & 28,45 & 39,5 vezes \\
Chuchu & 0,38 & 2,98 & 7,8 vezes \\
Couve-flor & 5,98 & 21,43 & 3,6 vezes \\
Couve manteiga & 2,15 & 19,75 & 9,2 vezes \\
Repolho roxo & 2,05 & 37,90 & 18,5 vezes \\
\hline
\end{tabular}

pelos consumidores é pacote ou bandeja, contendo apenas um tipo de hortaliça $(53,3 \%)$ e mais de uma porção por embalagem (59,6\%). Porém, isso não quer dizer que as outras opções não são aceitas pelos consumidores. Provavelmente o tamanho da porção está diretamente ligado ao número de pessoas que residem no domicílio, sendo que pessoas que moram sozinhas preferem embalagens com porção individual. Nota-se que as saladas minimamente processadas são também bem aceitas pelos consumidores, pois a diferença entre esta opção e a outra (apenas um tipo de hortaliça) é pequena (6,6\%). Enquanto no Brasil ainda é tímida a existência de saladas mistas, nos Estados Unidos atualmente é oferecida grande variedade de saladas folhosas com "kits" combinados com tomate cereja, torradas ("croutons") e molhos variados (Moretti, 2004).

Verificou-se ainda que o relacionamento entre os estabelecimentos e os fornecedores de hortaliças minimamen- te processadas é bom ou ótimo. O fornecedor é escolhido considerando-se os critérios de qualidade, pontualidade na entrega, preço e prazo de pagamento. Não há fidelidade de marcas, pois o produto é relativamente novo no mercado. Apenas sete empresas abastecem a grande maioria do mercado com esse tipo de produto em Belo Horizonte. Uma dessas empresas é uma cooperativa de agricultores orgânicos do interior de São Paulo. A maioria das outras são localizadas em Minas Gerais e são de menor porte.

Todos os produtos são expostos em balcão refrigerado com temperatura inferior a $10^{\circ} \mathrm{C}$. Não havia diferenciação aparente entre os produtos nas gôndolas, uma vez que um produto muitas vezes era encontrado em mais de uma prateleira em todos os estabelecimentos. As principais informações encontradas nas embalagens dos produtos minimamente processados eram: validade, data de fabricação, inscrições: "pronto para con- 
sumo", "lavado e higienizado", peso, recomendação para estoque refrigerado e ingredientes. Alguns fabricantes apresentavam informações nutricionais e selo de qualidade do Instituto Biodinâmico (IBD) para produtos orgânicos.

O preço relativo das HMP é muito elevado, chegando em alguns casos a quase 40 vezes em relação ao produto ao natural, como as cenouras (Tabela 2). Segundo cotação realizada durante uma pesquisa em supermercados de Minas Gerais, os preços destes produtos são, em média, cerca de $180 \%$ superiores aos das hortaliças vendidas a granel, chegando a alcançar valores de até $400 \%$, o que pode ser considerado um fator limitante no aumento do consumo dos pré-processados (FrutiFatos, 1999).

Pelo baixo consumo de hortaliças minimamente processadas, pode-se perceber que o mercado ainda não está consolidado em Belo Horizonte. As vantagens que este tipo de produto oferece ainda não são suficientes para incrementar as compras, e o principal motivo é o seu preço elevado.

\section{REFERÊNCIAS}

ANDREUCCETTI C; FERREIRA MD; TAVARES M. 2005. Perfil dos compradores de tomate de mesa em supermercados da região de Campinas. Horticultura Brasileira 23: $148-153$.
CANDEL MJJM. 2001. Consumers' convenience orientation towards meal preparation: conceptualization and measurement. Appetite 36: 15-28.

FRUTIFATOS. 1999. A importância dos préprocessados. FrutiFatos 1: 16-18.

FRUTIFATOS. 2003a. Um perfil dos investidores dos "sacolões". FrutiFatos 4: 6-7.

FRUTIFATOS. 2003b. Presença indispensável à mesa. FrutiFatos 4: 34-37.

IBGE - Instituto Brasileiro de Geografia e Estatística. 2004, março. Disponível em: www.ibge.gov.br.

International Fresh-cut Produce Association (IFPA). 2001. Food Safety Guidelines for the Fresh-cut Produce Industry. Fourth Edition. 2001. 213p.

JACXSENS L; DEVLIEGHERE F; DEBEVERE J. 2002a. Predictive modelling for packaging design: equilibrium modified atmosphere packages of fresh-cut vegetables subjected to a simulated distribution chain. International Journal of Food Microbiology 73: 331-341.

JACXSENS L; DEVLIEGHERE F; DEBEVERE J. 2002b. Temperature dependence of shelflife as affected by microbial proliferation and sensory quality of equilibrium modified atmosphere packaged fresh produce. Postharvest Biology and Technology 26: 5973.

JUNQUEIRA AMR; RIBEIRO ACF; GOMES RA; PERES RM. 2003. Perfil do consumidor de hortaliças minimamente processadas no Distrito Federal. In: CONGRESSO BRASILEIRO DE OLERICULTURA, 43. Anais... Recife: SOB. p. 1-4.

JUNQUEIRA AMR. 2002. Organização de plataformas - Agroindústria de Produtos de Origem Vegetal. Brasília: UnB. 150p.

LEATHER S. 1995. Fruit and vegetables: consumption patterns and health consequences. British Food Journal 97: 1017.
MATTAR FN. 1996. Pesquisa de Marketing. Edição Compacta. São Paulo: Editora Atlas. 270p.

MORETTI CL. 2004. Panorama do processamento mínimo de hortaliças. In: ENCONTRO NACIONAL SOBRE PROCESSAMENTO MÍNIMO DE FRUTAS E HORTALIÇAS, 3. Anais... Viçosa: UFV. p.1-8.

PIGAA; D'AQUINO S; AGABBIO M; EMONTI G; FARRIS GA. 2000. Influence of storage temperature on shelf-life of minimally processed cactus pear fruits. Food Science and Technology/Lebensmittel-Wissenschaft \& Technologie 33: 15-20.

RAGAERT P; VERBEKEB W; DEVLIEGHEREA F; DEBEVEREA J. 2004. Consumer perception and choice of minimally processed vegetables and packaged fruits. Food Quality and Preference 15: 259-270.

RAMOS SRR; FORTALEZA JM; ARZABE C; RIBEIRO VQ. 2005. Perfil dos consumidores de hortaliças na cidade de Teresina - Piauí. CONGRESSO BRASILEIRO DE OLERICULTURA. Resumos... Fortaleza: ABH (CD-ROM).

SEBRAE-Embrapa. 2003. Iniciando um pequeno grande negócio agroindustrial. Polpa e Suco de Frutas. Série Agronegócios. Brasília, 2003.

SILVA CAB; FERNANDES AR. 2003. Projetos de Empreendimentos Agroindustriais Produtos de Origem Vegetal, v. 2. Viçosa: Editora UFV. 459p.

VERBEKE W. 2001. Beliefs, attitude and behaviour towards fresh meat revisited after the Belgian dioxin crisis. Food Quality and Preference 12: 489-498.

VERLEGH PWJ; CANDEL MJJM. 1999. The consumption of convenience foods: reference groups and eating situations. Food Quality and Preference 10: 457-464.

WILKINS JL; BOWDISH E; SOBAL J. 2002. Consumer perceptions of seasonal and local foods: A study in a US community. Ecology of Food and Nutrition 41: 415-439. 